\title{
Identifying Top School Indicators in Education Transition Document
}

\author{
Identificação dos principais indicadores da escola no documento de transição \\ para a educação
}

\author{
Monir sadat Entezari' \\ Asgar Sharifill
}

\begin{abstract}
The purpose of this study was to identify the characteristics of the top school in the document of education transition. The research method was objective-fundamental and qualitative in terms of data type. The statistical population of the study consisted of the managers and staff of the Ministry of Education, the provincial administrations and the educational districts. Sample size in the qualitative section was determined by theoretical saturation principle of 23 people who were selected by purposeful sampling. In the present study, semi-structured interview tool was used for data collection. The validity and reliability of both instruments were confirmed. Data analysis was done by coding method. The results showed that the factors that constituted the top school in the transition document balance included moral, social, economic, political, bio / physical and scientific education and technology; Management, educational space and equipment, information technology, as internal and Islamic community requirements, media, family, educational justice, were external requirements.
\end{abstract}

Keywords: Transformation document indicators and requirements, Education, High School, Agility, Development, Continuous learning

\section{Resumo}

O objetivo deste estudo foi identificar as características da escola superior no documento de transição educacional. O método de pesquisa foi objetivo-fundamental e qualitativo em termos de tipo de dados. A população estatística do estudo consistiu dos gerentes e funcionários do Ministério da Educação, das administrações provinciais e dos distritos educacionais. O tamanho da amostra na seção qualitativa foi determinado pelo princípio de saturação teórica de 23 pessoas que foram selecionadas por amostragem

I Department of Educational Management, Roudehen Branch, Islamic Azad University, Tehran, Iran entezari@aftermail.ir

"Assistant Professor, Department of Educational Management, Roudehen Branch, Islamic Azad University, Tehran, Iran - sharifi@aftermail.ir 
intencional. No presente estudo, foi utilizada a ferramenta de entrevista semiestruturada para coleta de dados. A validade e a confiabilidade de ambos os instrumentos foram confirmadas. A análise dos dados foi realizada pelo método de codificação. Os resultados mostraram que os fatores que constituíram a escola superior no equilíbrio dos documentos de transição incluíram educação e tecnologia moral, social, econômica, política, bio / física e científica; Gerenciamento, espaço e equipamentos educacionais, tecnologia da informação, como requisitos da comunidade islâmica e interna, mídia, família, justiça educacional, eram requisitos externos.

Palavras-chave: Indicadores e requisitos de documentos de transformação; Educação; Ensino Médio; Agilidade; Desenvolvimento; Aprendizado contínuo 


\section{Introduction}

In today's changing world, organizations need to engage in a continuous process of change in order to stay away from global competition so that they can stand up to organizational issues while taking advantage of the complex and changing environment opportunities around them (JACOB ARIOLA ET AL., 2016: 56). In today's changing environment, organizations need to continually develop their abilities and competencies to respond to changing and changing environmental conditions (JANE BERG, 2016: 31). In the meantime, organizations, especially educational organizations, must adapt themselves to the pre-set goals of their education system and move forward flexibly with environmental change (VAN \& VAN HEILERSBERG, 2018: 234).Schools are the main educational institutions in society, as they are the first public and educational institution that children set up. Also, numerous historical studies show that educating exemplary and effective citizens for a society has always been one of the highest goals of the education system, including the education system, and that almost all educational systems formulate their programs in the ideology, worldview and philosophy of society (Peterson). WEBENTLEY, 2017: 108). Therefore, addressing schools and aligning schools with the goals of the education outlook should be clearly and properly done.

The topic of transformation in the education system is one of the fundamental issues in the education system which is very important from the perspective of policy, planning, management and implementation. The subject of change, in fact, has drawn the attention of educational officials for many years, largely because of the dynamic and continuous nature of the education system, only through an institutionalized process of transformation can educational goals be realized, and this can only be achieved through active and continuous participation. is not. Following changes and improvements to improve the educational situation, a document was prepared and adjusted based on comprehensive research and consideration of community development, which was in line with the Horizon 1404 Vision Document and the Comprehensive Scientific Plan of the Country and the Expediency Council Approvals. The document consists of eight chapters, which are the Statement of Values, Mission Statement, Vision, Macro Goals, Macro Strategies, Operational 
Goals and Strategies, and the Institutional Framework and Executive System for Fundamental Education Development. According to Chapter Eight, the Basic Education Transformation Document, to realize the goals and programs of the National Education Document, the Higher Education Council, using all the capacity of the Ministry of Education and other institutions and facilities of the country, to review, approve, and implement implementing policies, design and implement policies, Related structures and processes are responsible for updating, repairing, coordinating and integrating policies, programs, and overseeing the proper implementation of strategic transformation plans (FUNDAMENTAL TRANSFORMATION DOCUMENT, 2011). A document of fundamental evolution in education that is the result of a collective rationalization and strategic thinking aimed at transforming the foundations of education to achieve goals such as fostering a deep belief in Islam and its high values and ideas, and ultimately achieving the vision and goals of education (ABAZARI \& ZARGAR, 2016: 12).

The contents of the document on the fundamental evolution of education in relation to the categories under study in this study, although it has several strengths, but on some important and crucial issues such as the discussion of promoting and developing nationalIranian culture, expanding and strengthening Persian language and literature. The development of technical and vocational centers and conservatory of music, attention to fine arts, foreign language education, etc. have not been well addressed, leading to numerous challenges in the implementation and operationalization of this document. In sum, the fundamental transformation document for education in order to achieve what is defined in Outlook 1404 requires substantial reforms, developments, and transformations in relation to the categories examined in the present study (ISLAMI et al., 2015: 3).

Experts now consider the fundamental evolution in education to be three-fold: the "theoretical layer, the program layer, and the operational-executive layer." The theoretical layer is what is referred to as the "Theoretical Foundations of the Fundamental Transformation Document and the Fundamental Transformation Document". In the application layer, subsystem formulation is considered, and in the executable layer, executable programs will be developed and implemented. The document of fundamental change in education of education based on the teachings of the Qur'an, upstream 
documents, including the Twenty Year Vision Document (HORIZON $1404 \mathrm{AH}$ ), is a comprehensive scientific map of the country. The country's education goals are designed to meet the goals of a comprehensive document at the end of each course, but according to research, numerous challenges have been raised and not only have the goals of the document been implemented, but some education experts believe they have. Not even close. When it comes to education and implementation of the development document, comments are drawn to the school that symbolizes education. In fact, in the document of change, the school is also the changing pillar. Because it is defined as the center of formal education and learning environment in the document of fundamental change. In the Transformation Document, the school is a rich place for educational programs for all students, and its role is not only to enhance students' knowledge and skills, but also to prepare them in line with current and future community expectations. In such circumstances, and within the country's 20-year horizon, the school will become a place where students enjoy active participation and are reluctant to leave. At this school, the student participates not only in education but also in his religious and ethical training with teachers. Therefore, the student is the focus of activities. In other words, in this school, student-centered approach is emphasized along with subject-centered and teacher-centered approaches (HAJI BABAEI, 2012: 53). In this document, the school should be a suitable place for the human education of the believer and of Islamic ethics, familiar with, and committed to, the responsibilities and duties of God, himself, others, and nature; Self-sacrificing, patriotic, collectivist, waiting and universal-minded, willful, hopeful, self-confident, self-respecting, wise and capable, pure and honest, selective and free-spirited, creative and entrepreneurial and determined, healthy and arrogant, law-abiding and orderly Specialized training for decent individual, family and social life based on the Islamic standard system (HAJI BABAee,2013:53).

Accordingly, and given the challenges that scholars today point to in the absence of document goals in schools, planners and policymakers must consider the establishment and implementation of a school based on the document and its goals. And identify various factors that may affect this. 
BAZRAFSHAN et al. (2015: 28), in his research points to the role of managers in achieving the goals of the transformation document. Effective and efficient managers, he says, make the most of this success by making the most of the available resources and active and effective interaction with other components of the organization. Another important factor affecting teachers is a key pillar in schools; teachers have an effective role in the implementation of this document in schools. While they have not played a significant role in preparing this document, this is one of the challenges ahead. KARIMI et al. (1986) point out in their research the role of society in achieving the goals of the document of transformation. On the other hand, curriculum, financial resources, space, and equipment are also important factors influencing document-based school deployment (HEDAYATI \& KHARAZMI, 2016: 63). There have also been several studies in external research on the impact of different factors on the implementation of the educational landscape. BELL and HARRISON (2018), for example, consider teacher and management factors to be effective in better implementation of the educational landscape. In their research, ECKERT et al. (2018) examined teachers' professional qualification programs to achieve higher education and quality goals. This research is a descriptive-survey research and the results have shown that the promotion of teachers' professional competence affects the quality of education and achievement of high educational goals. CHATSIFATO (2018), in a study examines education for sustainable development: perspectives, policies and actions. This is a review study and the results show that teacher and educational environment have a significant impact on implementation of vision and policy and educational measures. Also, GLEEVE et al. (2018), in a study examined the evaluation of educational perspective and its scientific results. This research is a qualitative one and the results have shown that evaluation of educational perspective provided to schools has an impact on the scientific results obtained from school education. BEER et al. (2018), in a research study ideal school. This research is a qualitative one and the results show that different factors must be considered in order to reach the ideal school. These include the teacher, family, administrator, and curriculum. As stated, the implementation of a desirable school that is fundamental to the balance of change document requires additional efforts because in the current situation such a major failure has not been achieved and the schools have not implemented the goals stated in the 
transformation document properly. This can be well understood from studies that have examined the various challenges and obstacles to achieving document goals. Critics of the school believe that the lack of proper training for teachers and the lack of management support and the lack of technological structure that fits in with today's world, as well as the culture of a society that continues to use prescriptive rather than practical concepts, has not come close to the goals of the document. On the other hand, the Transformation Document itself has many critics who believe that it refers to a non-realistic idealistic society and ignores the phenomenon of globalization and increasing global change. Based on the aforementioned, the present study seeks to identify the challenges of not achieving the goals of the Transformation Document, to help establish a capable school in the Transformation Document, and to answer the essential question of the superior school characteristics in the Transformation Document. And what are the breeding?

\section{Research Methodology}

Given that the purpose of this study was to identify the top school indicators in the document of education transformation, the research method was applied-fundamental; in terms of data type, it was qualitative.

\subsection{Statistical population, sample size and sampling method}

The statistical population of the study consisted of the managers and staff of the Ministry of Education, the provincial offices and the educational districts. Samples were selected by purposive and judgmental sampling. The sample size was not determined and 23 individuals were selected based on the theoretical saturation principle.

\subsection{Data Collection tools}

The research tool consisted of semi-structured interviews that were used to answer the question about identifying the main components of the research and its characteristics. The details of the interview are as follows: 
Table 1 - Interview Profile

\begin{tabular}{|c|c|}
\hline Row & \begin{tabular}{c} 
Question \\
\hline 1
\end{tabular} \\
\hline 2 & $\begin{array}{c}\text { What is your definition of school implementation in the balance sheet of } \\
\text { fundamental change? }\end{array}$ \\
\hline 3 & $\begin{array}{c}\text { What do you think are the internal and external requirements for getting } \\
\text { to a top school? }\end{array}$ \\
\hline 4 & $\begin{array}{c}\text { In your opinion, to what extent can the identified requirements of the } \\
\text { document be fundamental to the realization of the goals of the country vision } \\
\text { document? }\end{array}$ \\
\hline 5 & $\begin{array}{c}\text { In your opinion, what are the barriers to implementing a top-level school } \\
\text { in the balance sheet of fundamental change? }\end{array}$ \\
\hline 6 & $\begin{array}{c}\text { What is the input, process, and output of the top school according to the } \\
\text { fundamental transformation document? }\end{array}$ \\
\hline 7 & $\begin{array}{c}\text { What are your suggested strategies for implementing and establishing a } \\
\text { school in alignment with the fundamental transformation document? }\end{array}$ \\
\hline
\end{tabular}

\subsection{Validity and Reliability of Research Tools}

Validity: The coding method was used by several researchers to determine the reliability and repeatability of the interview results.

Reliability: Reliability refers to the consistency of the research findings. Reliability of the interview is discussed in stages such as interview position, transcript and analysis. Also, the reliability of the interviewee indicates how to guide the questions. In the transcript validity, the intrinsic validity of the transcripts made during the typing of the texts by two individuals should also be noted. Considering the percentages reported by two coders during the classification of interviews is also a method for determining reliability. The rate (percentage) of in-subject agreement between the two coders (who should be $60 \%$ or more) for an interview (control analysis) is also a method for analyzing reliability. In the present study, the test-retest reliability and in-subject agreement method were used to calculate the reliability of the interviews. 
In order to calculate test retest reliability, several interviews were selected as sample and each was coded twice in a short interval. The codes were then compared at two intervals for each of the interviews. The retesting method is used to evaluate the consistency of the researcher's coding. In each interview, codes that are identical in the two time intervals are labeled "agreement" and dissimilar codes are identified as "disagreement". The method of calculating the reliability of the coding performed by the researcher in two intervals was as follows:

Reliability percentage $=2 *$ (Number of agreements): Total number of codes ${ }^{*} 100$

\subsection{Methods of data analysis}

Content analysis was used to analyze the qualitative data of the study. In this project, the qualitative data analysis steps were collected through open coding and axial coding. Open coding is an analytical process by which concepts are identified and their features and dimensions discovered from within. In the open coding phase, the researcher identifies concepts and expands them according to their properties and dimensions. At this stage, the researcher from the raw data base, prioritizes categories related to the phenomenon under investigation by segmenting information, formulating information categories about the phenomenon under study, asking questions about the data, Compare cases, events, and other phenomena states to find similarities and differences. In the next step, axial coding, the researcher places one of the categories at the core of the process being explored (the main dimension) and then links the other categories (components) to it. In this regard, the main components and related indicators were identified in this study. Therefore, in the first stage, the main components and indicators are based on the open and pivotal coding process of data from semi-structured and exploratory interviews. The conceptual codes were presented and the priority of each factor was determined based on the frequency of the concepts mentioned in the interviews. Concepts were the central unit of analysis for open and axial coding. When precisely analyzing the data, concepts were coded, either directly from the transcript of the participants' interviews or according to their common uses. The transcripts of the interviews were regularly reviewed to find out the main and sub-categories and the importance and priority of these categories. Data were analyzed at sentence and 
phrase level for each interview and conceptual codes were extracted from transcripts of interviews. Sometimes a sentence was related to more than one concept. By extracting common conceptual codes and by refining and removing duplicates, by applying the theoretical foundations and applying some conceptual codes, the concepts are identified and identified and by refining and reducing these concepts into subcategories (components) ) Were organized. Accordingly, the researcher in the axial coding stage is necessarily considering the role of the concepts obtained in explaining the pattern of school deployment in the transformation document, the sum of the categories derived from the raw data, the categories extracted into three categories, input, process and The outputs were categorized and their theoretical relationships were designed in the selective coding section. According to Strauss and Korben (1990), if this model is not used, the fundamental data theory will lack the necessary accuracy and complexity (p. 87).

\section{Results}

In this section, the research data are analyzed and evaluated using scientific methods. Since the research is of mixed type. Data analysis consists of two parts: qualitative data analysis. The following is an analysis of the content of the interview data.

\subsection{Qualitative data analysis:}

Question 1: What are the main and secondary school benchmarks in the document aligning the fundamental transformation document of education?

Question 2: What are the internal and external requirements and infrastructures required at school for the establishment of a document that aligns with the fundamental transformation of education?

23 experts were interviewed on the first question based on a semi-structured interview with 7 questions. This question was answered using the grounded theory approach and the MAXQDA software.

Factor analysis results show that out of 219 indicators, 20 main components can be identified. 


\subsection{Qualitative side findings}

Side Question 1: What are the Implementation Strategies for Balancing Documentation of Fundamental Education Transformation?

In general, based on the research background, theoretical foundations, interviews with experts, as well as document status analysis of the fundamental transformation of education and its constituents and indicators (moving from undesirable to desirable as well as maintaining and enhancing desirable status) executive mechanisms In order to implement the document, the basic educational transformation document alignment is given priority in the following table 2.

Table 2 - Implementing Mechanisms for Implementing the Documentation of the Basic Education Transformation Document

\begin{tabular}{|c|c|c|}
\hline Row & $\begin{array}{l}\text { Priority of implementing mechanisms for } \\
\text { implementation of the document Balanced } \\
\text { Education Transformation Document }\end{array}$ & Abundance \\
\hline 1 & Continuous school improvement & 21 \\
\hline 2 & $\begin{array}{l}\text { Developing and enhancing the professional } \\
\text { competence of teachers }\end{array}$ & 18 \\
\hline 3 & Enrich curriculum content & 17 \\
\hline 4 & Cultivation & 14 \\
\hline 5 & $\begin{array}{c}\text { Paying attention to ethical, socio-cultural and } \\
\text { economic education at the same time }\end{array}$ & 14 \\
\hline 6 & media literacy & 12 \\
\hline 7 & $\begin{array}{l}\text { To meet the needs and expectations of the } \\
\text { translators by observing Islamic standards }\end{array}$ & 11 \\
\hline 8 & Spreading Entrepreneurship & 11 \\
\hline 9 & Attention to national interests & 9 \\
\hline 10 & $\begin{array}{l}\text { Paying attention to the principle of all- } \\
\text { encompassing participation of all institutions and } \\
\text { factors contributing to the establishment of the } \\
\text { school in the balance of development document }\end{array}$ & 6 \\
\hline 11 & $\begin{array}{l}\text { Paying attention to the public education system for } \\
\text { educational policy and policy making }\end{array}$ & 6 \\
\hline
\end{tabular}




\begin{tabular}{|l|c|c|}
\hline 12 & Establishing educational justice & 4 \\
\hline 13 & $\begin{array}{c}\text { Focus on creating effective, effective, learner- } \\
\text { centered, equity-oriented, participatory, and } \\
\text { competitive schools; featuring forward-looking, } \\
\text { perfectionist, transformational, faithful, thoughtful, } \\
\text { compassionate, and trustworthy mentors }\end{array}$ & 3 \\
\hline 14 & Continuous research and evaluation to improve & 3 \\
\hline
\end{tabular}

Second Side Question2: What Are the Obstacles to Document Implementation?

In general, based on the research background, theoretical foundations, interviews with experts on the barriers to implementation of the document, the fundamental balance of education reform document is presented in the following table 3 .

Table 3 - Barriers to Implementation of the Document The Balance Sheet of Basic Education Transformation

\begin{tabular}{|c|c|c|}
\hline \multirow{12}{*}{$\begin{array}{l}\text { Interference } \\
\text { or obstacles }\end{array}$} & $\begin{array}{c}\text { Priority of implementing mechanisms for } \\
\text { implementation of the document Balanced } \\
\text { Education Transformation Document }\end{array}$ & Abundance \\
\hline & Continuous school improvement & 22 \\
\hline & $\begin{array}{l}\text { Developing and enhancing the professional } \\
\text { competence of teachers }\end{array}$ & 18 \\
\hline & Enrich curriculum content & 18 \\
\hline & Cultivation & 15 \\
\hline & $\begin{array}{l}\text { Paying attention to ethical, socio-cultural and } \\
\text { economic education at the same time }\end{array}$ & 14 \\
\hline & media literacy & 13 \\
\hline & $\begin{array}{l}\text { To meet the needs and expectations of the translators } \\
\text { by observing Islamic standards }\end{array}$ & 11 \\
\hline & Spreading Entrepreneurship & 10 \\
\hline & Attention to national interests & 8 \\
\hline & $\begin{array}{l}\text { Paying attention to the principle of all-encompassing } \\
\text { participation of all institutions and factors contributing } \\
\text { to the establishment of the school in the balance of } \\
\text { development document }\end{array}$ & 8 \\
\hline & $\begin{array}{l}\text { Paying attention to the public education system for } \\
\text { educational policy and policy making }\end{array}$ & 7 \\
\hline
\end{tabular}




\begin{tabular}{|l|l|c|}
\hline & Establishing educational justice & 3 \\
\cline { 2 - 3 } & $\begin{array}{l}\text { Focus on creating effective, effective, learner-centered, } \\
\text { equity-oriented, participatory, and competitive } \\
\text { schools; featuring forward-looking, perfectionist, } \\
\text { transformational, faithful, thoughtful, compassionate, } \\
\text { and trustworthy mentors }\end{array}$ & 22 \\
\hline Continuous research and evaluation to improve & 18 \\
\hline
\end{tabular}

\section{Discussion and conclusion}

By examining the first question of the research on identifying the main and secondary school indicators in the Education Transformation Document, the research findings showed that educational factors such as ethical, social, economic, political, biological and physical education and science and technology are among the indicators. And in other words, the characteristics of the school are in the balance of the fundamental evolution of education. Given the challenges that threaten education in the country, such as modern technologies and environmental uncertainties, education as an organization that is a scapegoat in all areas of society must take into account various factors, one of the strategies that education can address. Repeating the problems and turning the schools under it into Bratz and empowering schools is the focus of upstream documents such as the fundamental transformation document. In the present study, it has been suggested that in the Transformation Document, the school is a enriched place for educational programs for all students, and its role in addition to enhancing students' knowledge and skills, is to prepare them in line with current and future community expectations. In such circumstances, and within the country's 20-year horizon, the school will become a place where students enjoy active participation and are reluctant to leave. The other element mentioned in the Transformation Document for the Superior School is the Social Education component. In this type of education, students are trained to become professional and ethical citizens. Citizens who are responsible for their own affairs and are not indifferent to their kind. Also, social 
education refers to social accountability and restructuring. Students undergoing this education are accountable for their mistakes and maintain their interactions with the world around them. The school has a leadership role in this area and leads students towards positive social interactions. Economic education is also highly valued, in today's economy the economy is at the forefront, so ways to earn profits and produce in schools should be used as ways to train economic experts. Learning economic literacy, commercialization, and how to produce are examples of economic education. With all these interpretations, one should not overlook the important feature of the top school, that is, political education. Political education leads to increased political literacy. With this kind of education, students learn how to analyze what is going on around them and what efforts they can make to enhance their political vision. Also, given that today there is war but a soft type that relies heavily on political literacy, so having political literacy helps students identify the consequences and factors of soft ware. Biological and physical education is also very important. This kind of education is also mentioned in the document of fundamental transformation, and schools are called high schools that first introduce students to physical and environmental health. Students, as the future-makers of the country, need to know what the earth is about to destroy and how we, as Ashraf creatures, have a mission and how to protect it. Environmental literacy, understanding physical and mental needs, and acquiring knowledge of individual and collective health care concepts that are addressed in biophysical education, but today's world is complex and countries are at the forefront of progress and development that go hand in hand. Move with the technologies of the day, and that requires training. One of the goals of top schools is to target lesson based on new technologies. Accordingly, e-learning, as one of the factors of learning in the digital world, should be given special attention. What is mentioned in the document of fundamental change and in other countries is used as a factor of progress and agility. Information technology should also be used for scientific research. Technology-based education facilitates this and teaches students that learning should not rely on a specific resource and that there should be no end-to-end learning. In the present study, it was also suggested that factors need to be taken into account for the implementation of the top school in the Transformation Document Balance, which has the characteristics mentioned above. These 
factors are the causal factors superior to school implementation. In the present study, causal conditions were examined in two parts: internal factors or external requirements and external requirements, and the results showed that internal factors, such as, teacher, curriculum, management, educational environment and information technology are involved. It should be noted that, first of all, the factor that plays the most important role in the process of school education is the teacher. The teacher is, in fact, a pivotal factor whose knowledge, skills, and attitudes toward learning and education have many consequences. Taking into account the findings of the philosophy of education as well as the meaning of education, the teacher can be regarded as a wise trustee whose task is to plan, educate, support, counsel, feedback and persuade students to challenge current opportunities to expand their existing capacities. Is responsible. The teacher at this school is able to identify his / her strengths and weaknesses and can improve his or her mental and intellectual maturity. It can organize its education and training programs in such a way as to provide the basis for the development and development of existential capacities and the achievement of students for the most part of life. The next component to consider is the curriculum. In fact, the syllabus is a set of systematic and planned educational opportunities at different levels that students are exposed to to acquire the skills necessary to understand and modify their situation so that they can achieve an acceptable degree of life by continually developing and enhancing their identity. Tayebeh includes all aspects and includes four dimensions of design, formulation, implementation and evaluation. The syllabus helps implement the top school in both explicit and hidden types of content. Management is another important element of the school's internal requirements. Management means strong and effective school management. Strong and knowledgeable management and leadership is one of the most important elements of this school. In addition to its executive function, its leadership function is more prominent and important in the school. At this school, the principal is eager for the school, the teacher and the student. He has a holistic view, passionate about change and leading it according to the circumstances, high personal and interpersonal efficiency, rational and transparent in conducting affairs and communication, stimulating human capital abilities, enhancing the participation of people and leading the activities to reach. It is great. 
The school document also mentions the educational space and equipment available at the school.

But it is not only the internal requirements of the school that influence the implementation of the school in the balance of development document, there are also external factors that affect this. The present study addresses factors such as Islamic society, the media, the family and educational justice. The basis of an Islamic society is the rule of law. In such a society, the law is accepted and enforced by everyone. The law also emphasizes the implementation of documents such as the Transformation Document. On the other hand, Islamic society has its core mission, and when it is pervasive throughout society, it affects the schools and ultimately the students. Strengthening social participation is another indicator of Islamic society. Students who grow up in such a society can think of an empowering and superior school. In the meantime, one should not ignore the educational awareness of the media. The media has a huge responsibility in today's world, while also having a significant impact on the social relationships and performance of various organizations, especially educational organizations. The media should promote the process of socialization, socialization, and participation in students and schools, and be able to inform half of the students' education informally. Educational justice, which rules in society and throughout the country, is another important factor that promotes fairness and equity in schools. When students, teachers, administrators, and all educational agents see that justice is done in the community and all organizations act on it, they are bound to follow it and achieve it. Distinguishing between learners of different gender, ethnicity, and race is one of the most prominent examples of attention to educational justice. Students learn about justice in society, but at first they understand it and grow in another institution called the family. The fundamental change document emphasizes the family's educational role and role and enhances its participation in effective interaction with the formal and public education system. In addition to what has been said in the present study, the implications or, in other words, the implications of the creation of a higher school in the developmental balance sheet are mentioned, and the findings of the research include the implications of agility, continuous learning and development. It has been said that the school in line with the evolution of the document will be fully developed, with full education in all areas of social, 
economic, political, environmental and technological development. Such a school is moving and accelerating things as the current world changes. It is an agile school and does not easily understand change, but looks at opportunities to make the best use of it. On the other hand, such a school pays close attention to the improvement of the professional competence of its agents and always provides training to enhance their competence. Moreover, such a school is booming and transcendent, as the participation of the members of the school speaks for itself and everyone steps in and redefines each other on the basis of a predetermined mission and environmental change. This is where continuous learning takes place. A learning culture that no longer has an end, and students donate it to the community after leaving school. By reviewing the theoretical foundations and using the experts' point of view, the present study proposes mechanisms to implement the document to align the fundamentals of education development, including continuous school improvement, teacher development and professional development, enriching curriculum content. , Culture, paying attention to ethical, socio-cultural and economic education at the same time, media literacy, meeting the needs and expectations of translators, observing Islamic standards, promoting entrepreneurship, attending to national interests, paying attention to the principle of all-round participation. And the factors contributing to the establishment of the school in the balance of evolution document Public education system for educational policy making and policy making, educational justice, attention to efficient schools, effective, learner, justice oriented, participatory and competitive; possessing futuristic managers, perfectionism and change makers, faithful coaches, thoughtful Compassionate and trustworthy, the foundation of a global justice community and continuous research and evaluation to improve the situation. In addition, barriers to implementation of the EDF document were also identified in the present study, including the coordination of principals and staff mental plans with the fundamentals of the EDF, lack of adequate budget allocation to schools for full implementation of the document. Transformation, lack of convergence between fundamental change and beliefs of education managers, centralized and bulky staff structure and lack of agility in schools, lack of family support, lack of media support, lack of passion for culture among teachers and teachers, lack of dynamics in school activities, lack 
of Attention to educational justice, rational management, lack of culture of transformation Creating a community in the current way, taking the exam in the current way, are micro and macro injuries in the education system and lack of attention to technology.

Concerning the findings of the present study, some studies are consistent. Bazrafshan et al. (2015: 28), in his research points to the role of managers in achieving the goals of the transformation document. Effective and efficient managers, he says, make the most of this success by making the most of the available resources and active and effective interaction with other components of the organization. Another important factor affecting teachers is a key pillar in schools; teachers have an effective role in the implementation of this document in schools. While they have not played a significant role in preparing this document, this is one of the challenges ahead. KARIMI et al. (1986) point out in their research the role of society in achieving the goals of the document of transformation. On the other hand, curriculum, financial resources, space, and equipment are other important factors influencing document-based school deployment. There have also been several studies in external research on the impact of different factors on the implementation of the educational landscape. Bell and Harrison (2018), for example, consider teacher and management factors to be effective in better implementation of the educational landscape.

\section{References}

Abazari, Ali and Zargar, Ali. A Critical Analysis of the Documentary Evolution of the Iranian Education System, Challenges and Problems. National Conference on Electrical, Computer and Mechanical Engineering of Iran, 2017.

Arriola, K. R. J., Hermstad, A., Flemming, S. S. C., Honeycutt, S., Carvalho, M. L., Cherry, S. T., ... \& Kegler, M. C. Promoting Policy and Environmental Change in Faith-Based Organizations Outcome Evaluation of a Mini-Grants Program. Health promotion practice, 17 (1), 146-155, 2016.

Beare, H., Caldwell, B. J., \& Millikan, R. H. Creating an excellent school: Some new management techniques. Routledge, 2018.

Bell, J., \& Harrison, B. T. Vision and values in managing education: Successful leadership principles and practice. Routledge, 2018.

Chatzifotiou, A. Education for Sustainable Development: Vision, Policy, Practices-An Open 
or Closed 'Doorway' for Teachers and Schools? In Handbook of Lifelong Learning for Sustainable Development (pp. 197-209). Springer, Cham, 2018.

Come on, Mojtaba, Shoghi, Mercy and Merciful, Rachel. The Supervision and Guidance Position of Education in the Fundamental Transformation Document in Education. Journal of the Foundations of Education, 5 (2), 23-23, 2013.

Document on the Fundamental Evolution of the Education System. The Document on the Fundamental Evolution of the Educational System, developed in collaboration with the Supreme Council of the Cultural Revolution and the Supreme Council of the Ministry of Education, 2011.

Egert, F., Fukkink, R. G., \& Eckhardt, A. G. Impact of In-Service Professional Development Programs on Early Childhood Teachers on Quality Ratings and Child Outcomes: A MetaAnalysis. Educational Research Review, 0034654317751918, 2018.

Ginsburg, L., Berta, W., Baumbusch, J., Dass, A. R., Laporte, A., Reid, R. C., \& Taylor, D. Measuring Work Engagement, Psychological Empowerment, and Organizational Citizenship Behavior Among Health Care Aides. The Gerontologist, 56 (2), e1-e11, 2016.

Glewwe, P., West, K. L., \& Lee, J. The Impact of Providing Vision and Free Eyeglasses on Academic Outcomes: Evidence from a Randomized Trial in Title I Elementary Schools in Florida. Journal of Policy Analysis and Management, 37 (2), 265-300, 2018.

Haji Babaei, Hamid Reza. Characteristics of the "school I love" according to the document of fundamental change in education. Educational Innovation, 11 (42), 74-51, 2013.

Hans, E., \& van Hillegersberg, J. A Framework for Planning and Control of the Education Organization. Smart Education and e-Learning 2018, 99, 234, 2018.

Hedayat, Angel and Kharazmi, Rahmatullah. Pathology of Implementation of Transformation Document Programs Based on Organizational Transformation Management Basics. Development Strategy, 45, 259-240, 2017.

Islamian, Hassan Mojgan Jahanbakhsh and Marzieh Rahmani. An Analytical Look at the Challenges of Implementing a Fundamental Transformation Document in Education, First International Conference on Management, Economics, Accounting and Educational Sciences, Sari, Future Research and Consulting Company, Payame Noor University Neka, 2018.

Karimi, Mehdi, Karimi, Ali, Porfiz, Mojtaba and Karimi, Zari. The Place of Educational Goals in the Document of Fundamental Education Change. Third National Conference on Modern Research in Humanities and Social Studies in Iran, 2018.

Mohammadi, Masoumeh, Salehi Omran, Ebrahim Pasha, Reza. Investigate the implementation of a substantial amount of money for education and training of managers. 
Futures Studies and Policy Making, 3 (6), 76-59, 2018. 